\title{
A Study on Interactive Media Art to Apply Emotion Recognition
}

\author{
Hae Young Lee ${ }^{1}$ and Won Hyung Lee ${ }^{1 *}$ \\ 1, 1* Graduate School of Advanced Imaging Science, Multimedia \& Film, Chung-Ang \\ University \\ allee4@naver.com,whlee@cau.ac.kr
}

\begin{abstract}
Digital technology has changed the method of traditional art works such as painting, sculpture and installation. Media Art that use the digital technology is in a range of Media Art. The difference between the traditional art and Media Art is about nteroction with audiences and art works. The introduction of technology is able to connect vinual reality, augmented reality and mixed reality to the real world or bring the audience to far away virtual space. Experience in a virtual world helps to feel a new things that people cannot experience in a daily lives. That can be escape from reatity and gives mysterious feeling. Theses virtual world make interaction with user and virtuat world. Offering virtual environment is important elements that appear $n$ Interactive Media Art. In front of the art works offers virtual reality, audiences import their emotions and able to change the environment of the art work. This paper will analyze about the new paradigm of Media Art works that adapt an emotion recognitionsystem in an art works developments in a short future, organize an Interactive Art theonies and concept of Emotion Recognition system and propose a concept about future art works.

Keywords: Interactive Art, Media Art, Emotion recognition, Audience Response, Cybernetic Art

\section{Introduction}

Modern ar express freely their feature to deny the method of traditional paints or sculpture after Dadaism. The new media technology appearance can digitize an expression mode of an art and artists use the nem-media to their art works to create a Media Art. In 1960s, artists were concerned to armachinery media and video art started from Nam Jun Peak took the lead in art field in 1970 s and 80s. However, after 1990s, new media art based on computer influence has been raised, and not only artists but also an engineer who is skillful at computer plans a development of new media art.

Almos of the audiences who receive a Media Art that use computer technology approach to it with interest of a new interface. They shake their hands and arms here and there and stamp their feet in front of the responsive art works with visually or auditory. They slowly into vesponsive art work and try to find any new visual or auditory elements through their body movement.

The traditional arts such as painting or sculpture are a static product that takes psychological interaction preferentially, however Media Art use mass media to occur not only psychological interaction but also material interaction. The communication with public has changed from metaphorical to direct. Media Art is becoming our daily lives over the art in these days. These types of art works made with "a holistic network form" which demands the complete participation of the audience. For this Popper defined participation indicates "the
\end{abstract}


relationship with completed art works", interaction means "the relation between the users and the system with intelligence" [1].

Won Kon Yi classifies the difference of virtual space and virtual reality according to the interaction existence. The space that we have in pervious painting, Photograph and movie was not the reality space, it just helps to feel the sense of reality. However, virtual reality is the situation of awareness the virtual reality as reality through interaction [2]. Interactivity elements are rising to one of the most important feature of Media Art in these days. Participation appeared as a form of 'Happening' in 1959. We can see Happening in Allan Kaprow's (18 happenings in 6 parts), actors or author announce in public as a performance form. After that multi-media experimental art works were progressed as the Fluxus center, behavioral component appeared in art works and audience started to participate with the art works [3].

Emotion is the most influential factor to the mental life of human. Audiences wo watch, use participate to the art works definitely feel something. Emotions are a psychological experiment from internal and external sense by stimulation of human. Emotion use with similar word effect coincidentally, however, generally Affect is a concept that include Emotion and Mood. Emotion is similar to Affect and it contains define cause and response. Expressive behavior such as face expression and physical body expression, physiological wake up such as excitement of autonomy nervous system and it contains behavioral tendency. Individual probably cannot feel the emotion consciously. Emotion experience consciously holds for short period. Emotion can be categorized to positive emotion and negative emotion. Low categories of the negative emotions are nore than the positive emotions [4].

In this paper, through the concept of future Interaciye Media Art work 'The Universe' applied Emotion Recognition system, we Will research how it effect on audience's behavior and participation though case studies.

\section{Feature and the Effect of Interactive Media Art}

This chapter based on the case study research, analyze Interactive Media Art essential elements.

\subsection{Interactivity $n$ Media Art}

Interactive media appearance provides the cause of innovative changes in existing media environment and it mean the innovative change of communication mode. Interactive Art is form of art that communicate with audiences not just deliver the artist's idea or purpose to the audience unilaterally.

Other than the traditional art the present Media Art involve the audiences in the art works process to complete it. People were interpret the traditional art by watching it, however, now the audierces create the art works with their participation. Media Art works is an experiment in interaction and the art work itself and the audience (normally in Interactive Media Art in dicate them as 'user') can be separated and explored. Artist is not the sole who create the art works in Media Art. Murray analyzed about the characteristic of digital media is procedural, participatory, spatial and encyclopedic. Procedural and participatory feature means the aspect of interaction. The changes of form cause the changes of contents.

Interaction in art is an aspect of communication each other and it begins in late 1950s and 1960s participation work. Popper mentioned the necessary of classification about 'participation' and 'interaction'. Participation indicates the participation in 1950s and 1960s performance and video art. The video artist Nam June Paek and other Fluxus artists were so into create their work with the audience's active participations. Myron Krueger who is the 
media artist concerned on interface design. He emphasized that artists are able to read the interactive interface technological and aesthetic level at the same time. He concentrated on 'Responsive Environment' and created 'Videoplace'. It represents reaction of audience with the environment and focused on realistic embodiment of interaction. The concept of this art work is simple. It consists of two or more rooms that can be placed anywhere from next to each other to thousands of miles apart. Within the room, a $8^{\prime} \times 10^{\prime}$ rear projection screen is utilized so that when a person enters, they are confronted with their own image as well as the images of those in the connected rooms. Those in the connected rooms are also witnessing the same image that the user himself sees. By moving about the their respective rooms, the user's image itself moves about and can interact with other users' images. In addition, the user's image can be shrunk, rotated, colored or keyed in various ways. The user also has the chance to interact not only with the other users, but with graphically represented objects [5]. Krueger says "The video medium has the potential of being more rich and variable in some ways, than reality itself."
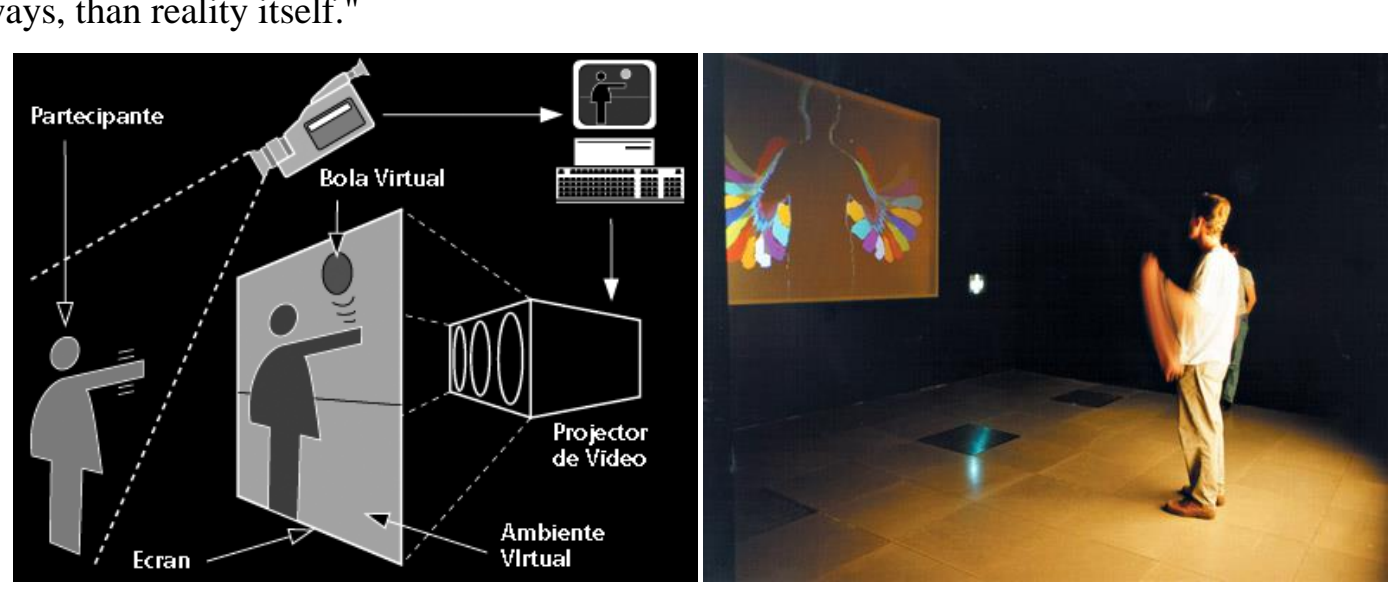

\section{Figure 7 Myron Krueger <Videoplace>, 1975}

We found some more example of Interactive Media Art that works with audience participation. Figure 2 is an Interface and body in interactive art. Body function methods that how reflect on art works in Interactive Digital Art works can be divided into three types. The first type is project the audience as it is on an art work like 'Text Rain' (Figure 2). 'Text Rain' shows the most basic feafure of interaction in a new digital environment. The audiences are able to watch themsepres directly so they can build up their expanded ego and they manipulate the digiar environment through the feature of themselves in a virtual space [6].

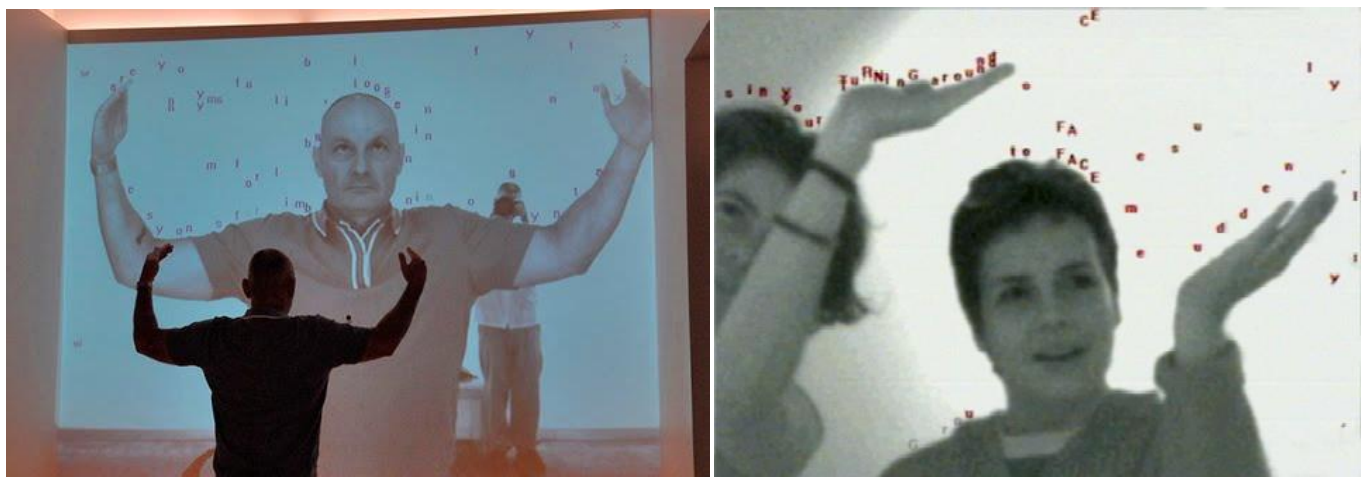

Figure 1. Rony Achive \& Camile Utterback, <Text Rain>, 1999 
Shadow Garden was displayed in Siggraph 2002 is developed by Mind Control company in San Francisco, USA. Shadow Garden shows communication between the user and computer without electronic devices such as keyboard or mouse. At the first project images create from computer on a wall or on a screen. When the user stand in front of the projector then shadows on covered the images. Digital camera placed on the wall to deliver the shadow signal to computer. The computer has a real time response algorithm for monitored images so images that are response from the shadow is generate. To project the generated images through projector as if it responds to the shadows. The users try to create great images so they can feel excitement to be a part of the art works.

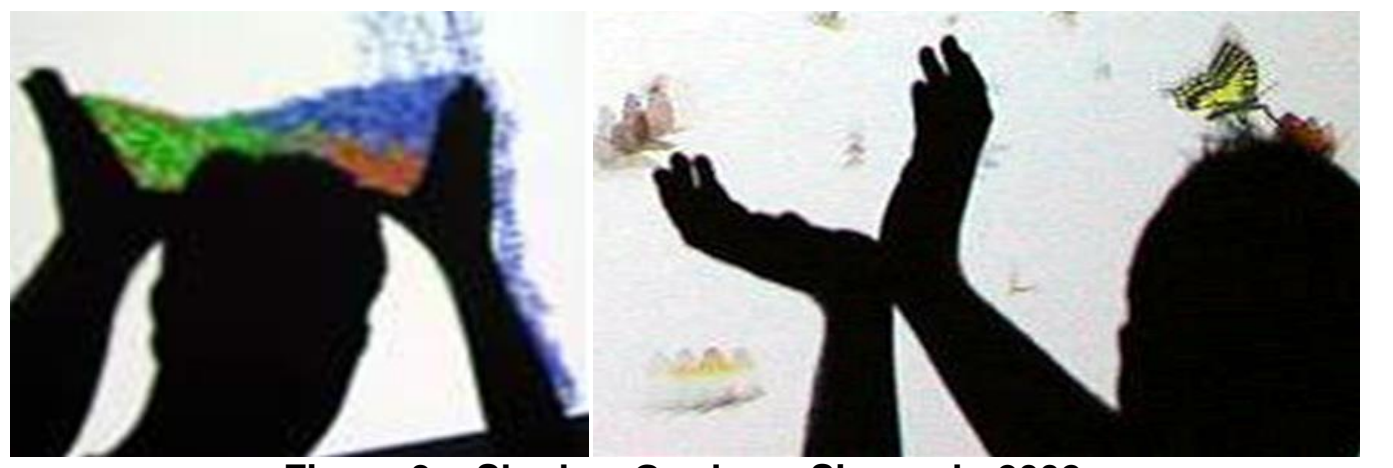

Figure 3. <Shadow Garden>, Siggraph, 2002

The second Interactive Media Art is from Mind Control in 2004. This is a virtual reality concept performance in virtual space. When the audience act like draw something with hand in front of the screen, a camera thagnclude move sensor reads the action position and tree like image draws on the screen. If the user takes off the hands from it the tree branch falls off and disappeared [7].
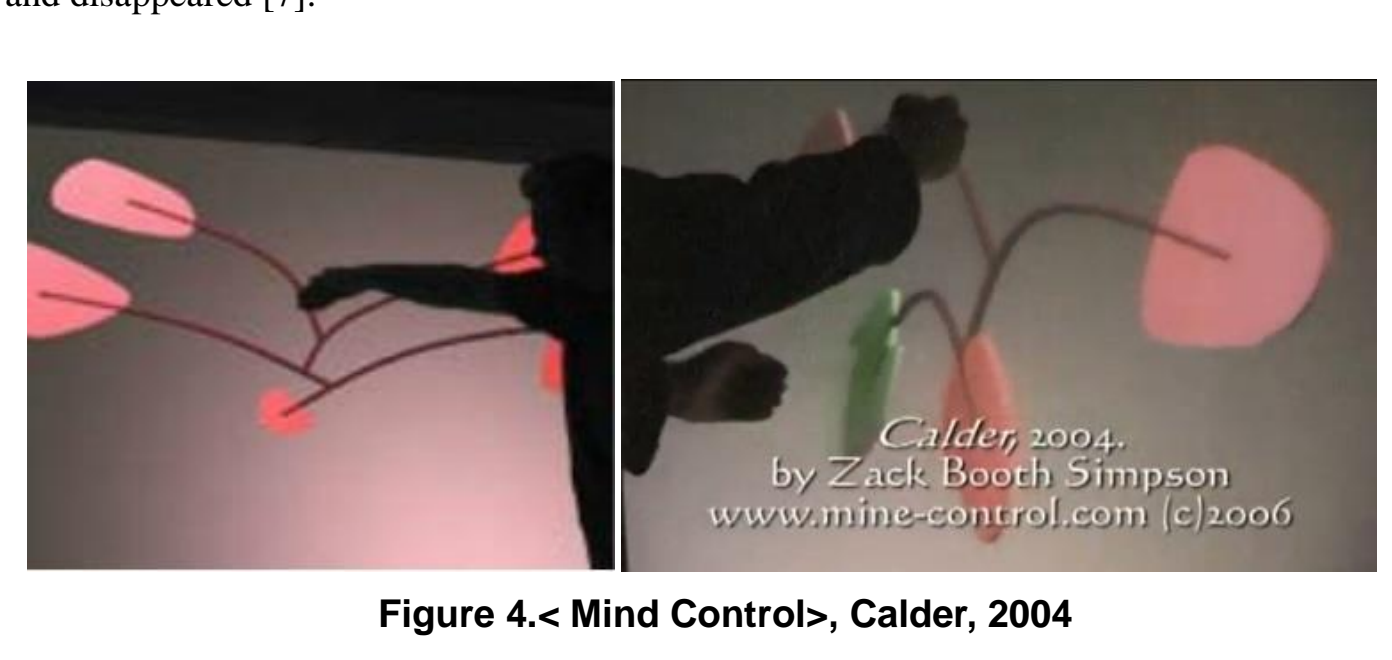

Interactive Media Art produces live images and communicates with the users in spontaneous way by use of various media. To reflect the reaction of the audience, appears spontaneous response and the changing process in space accept naturally. Christine Paul says artists are not the sole creator; they are more like mediator and advisor for contribution of interaction and audience with art works. Media artist shows messages of their work through the audience's participation. Today's Media Art is a communicational works that mostly complete with the audience's intervention. Commutation is not only reestablishing the 
relationship between artist and art enjoying reader but also it changes the form of art action itself.

\subsection{Extension of Cognition and Perception through Virtual Reality}

Media is extension of human body (Marshall McLuhan). Media spread actively experiment crossing various genres or build a new genre territory. The space between Science and Art, Technology and Art, Technology and aesthetic are becomes meaningless and the boundary of high art and public culture industry become faint [8]. The most advanced form of combination science technology and art is interaction between the audience and artist in virtual reality. When artist open the virtual reality with simulation work then audience intervene to the art work use navigation and interface of the virtual environment [9]. The appearance of Cyberspace and virtual reality create not only a new space for an art action, it makes the artists and the audiences are able to interact together. Cyberspace is "the notional environment in which communication over computer networks occurs" [10]. In the other words, the most powerful character of virtual space which distinguishes from real world is that is a fictional world that can watch and feel without rear. We understand about virtual reality that it is 'alike to real' but 'not a real'. However, the development of Inedia technology makes virtual reality look more realistic. Therefore, virtual reality is the expansion of reality. The desire to make impossible things to possible in reality connects tocreate a new real space. Moreover, we can understand the virtual reality as completely new space creation. Separate from reality and build a concluded virtual space by itself Vutual reality features can be organized as Table 1 [11].

\section{Table 1. Feature of Virtuar Reality}

\begin{tabular}{|c|c|c|}
\hline No & Feature of Virtual Reality & Explanation \\
\hline $\mathbf{1}$ & $\begin{array}{l}\text { VR have its own time and } \\
\text { spatiality. }\end{array}$ & $\begin{array}{l}\text { It does not have physical substance but it has equal } \\
\text { attributes like physical world. }\end{array}$ \\
\hline 2 & through & $\begin{array}{l}\text { Each user can experience it in a real-time with same } \\
\text { behavior like reality. Exchanging information among } \\
\text { the users in virtual space transcend time and space. }\end{array}$ \\
\hline 3 & the realistic & $\begin{array}{l}\text { User experience the presence even not easy to } \\
\text { distinguish that happens in a real world or in a virtual } \\
\text { world. Moreover, virtual reality provides more } \\
\text { tension and dramatic sense than real world. }\end{array}$ \\
\hline & Duplicity space. & $\begin{array}{l}\text { Imitation and pursuit the physical world and focus } \\
\text { the interest in psychological world. }\end{array}$ \\
\hline 5 & Phantasm image world. & Offers imaginary world that user can feel by itself. \\
\hline
\end{tabular}

Audience experiences a fictional reality equally to real reality. It represent the virtual reality interface as mediation and it is also a highly space that transcendence cognition and 
senses. [12] Audiences are immersed in virtual reality space. The virtual environment stimulates five senses of the audience and offers similar space and time experience to reality. The work form Jaffrey Shaw 'The Legible City (1988)' is a responsive environment in a virtual world. It created Institut für Neue Medien in Frankfurt/M., are seated on a stationary bicycle and 'move' through streets projected onto the surface in front of them. In contrast to those of a normal city, the streets here are literally legible, lined not by buildings but by letters. On their passage through the city, cyclist-visitors can pursue various narrative threads, accumulating their own history of the city. They can feel like they are on a journey in virtual environment due to the moving images on screen.
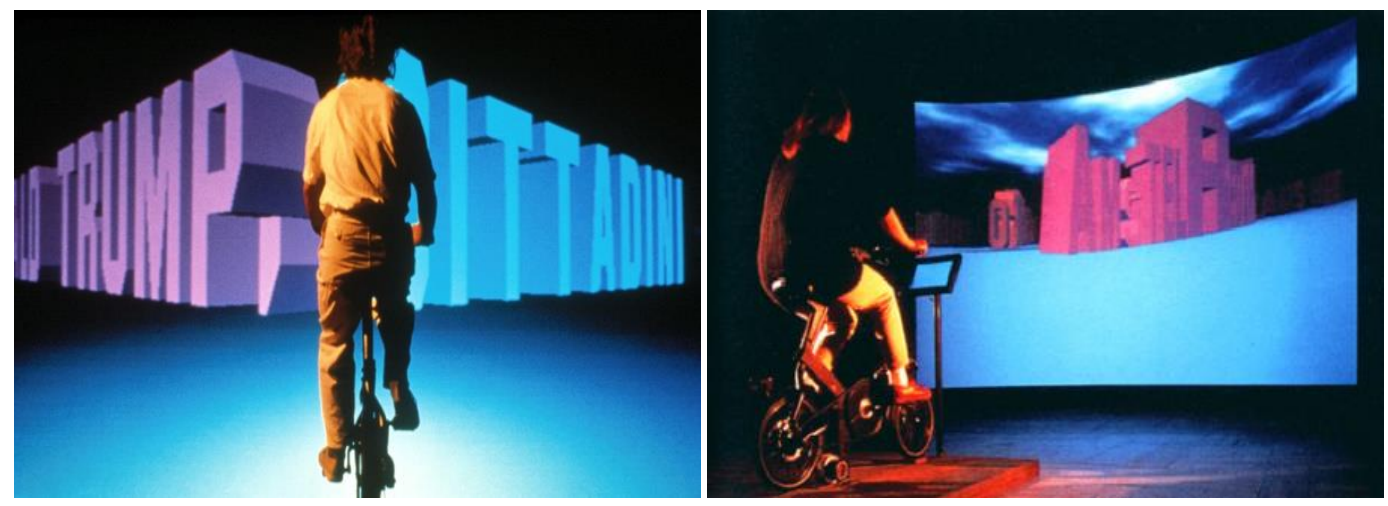

Figure 5. Jaffrey Shầ, <The Legible City>, 1988

\section{Emotion Technology}

Emotion is a subjective, conscious Cexperience characterized primarily by psychophysiological expressions, biological reactions, and mental states. Emotion is often associated and considered reciprocally influential with mood, temperament, personality, disposition, and motivation [13]. Human emotions classify to the basic 6 emotions (angry, surprise, happy, sad, disgust and fear).

\subsection{Concept and Definition of Emotion Recognition}

Emotion gives vitality and the vitality raise up one's life and emotion. Emotion is one of the important facts to express sates of mind. We can express how we feel like with simple facial expression. Homan as innate or through experience in life, we have ability to cognize the right emotion in each situation. Human Computer Interaction (HCI) system is the field that emotion recognition system can be used widely. In the intelligent HCI system, computer recognize the user's emotion through the combination of face video, pupil position, gesture and vojee and from the state of emotion user can be satisfied with right performance [14].

\subsection{Case Studies on Interactive Media Art to Applied Emotion Recognition System (EEG)}

In this chapter we searched some related art work that use Emotion Recognition system. 


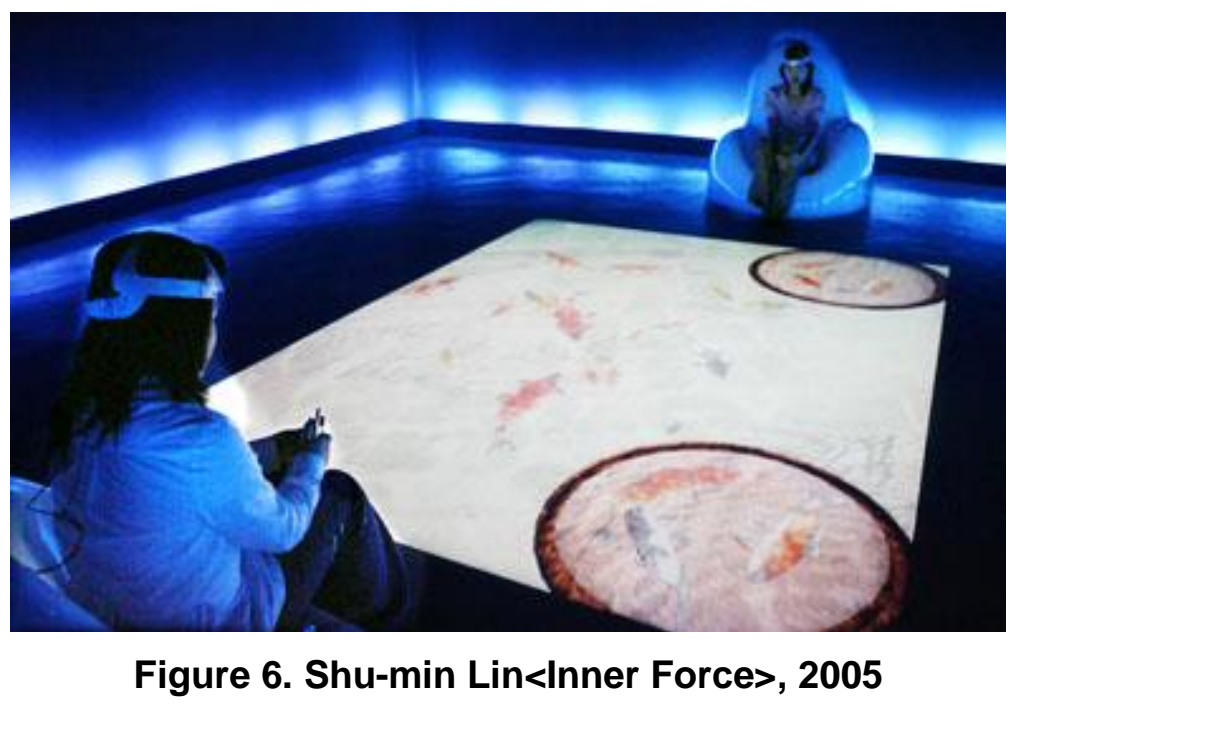

Science Art is one of the Media Art genres that express artist's message using the cutting edge science technology. It destroys the boundary between science and art and delivers thoughtful message with the audience's curiosity. Shu-Min Lin's work Inner Force applies to the practice of the wu-wei principle of Taoism, which means "action without competitive or selfish goals". It use brain wave monitor A pool of water is projected on the floor. "Participants have to compete to fill its surface with lotus flowers or to catch as many of the carp swimming in the water as possible Electroenceplalogram probes are attached to the viewers' heads to measure the alpha wave activity of the brain. Forcing things does not work, the more peaceful the posture and themind, the more successful the effort" [15].

The next case art work is Global Mind is an ongoing collaborative project. It inspired and led by multimedia Australian artist Karên Casey, Using software envisioned by Casey and designed by binary guru Harry Sokol. Global Mind project uses real time EEG brainwave activity to create and manipulate visuals and audio, from the direct point of conscious creation art event.

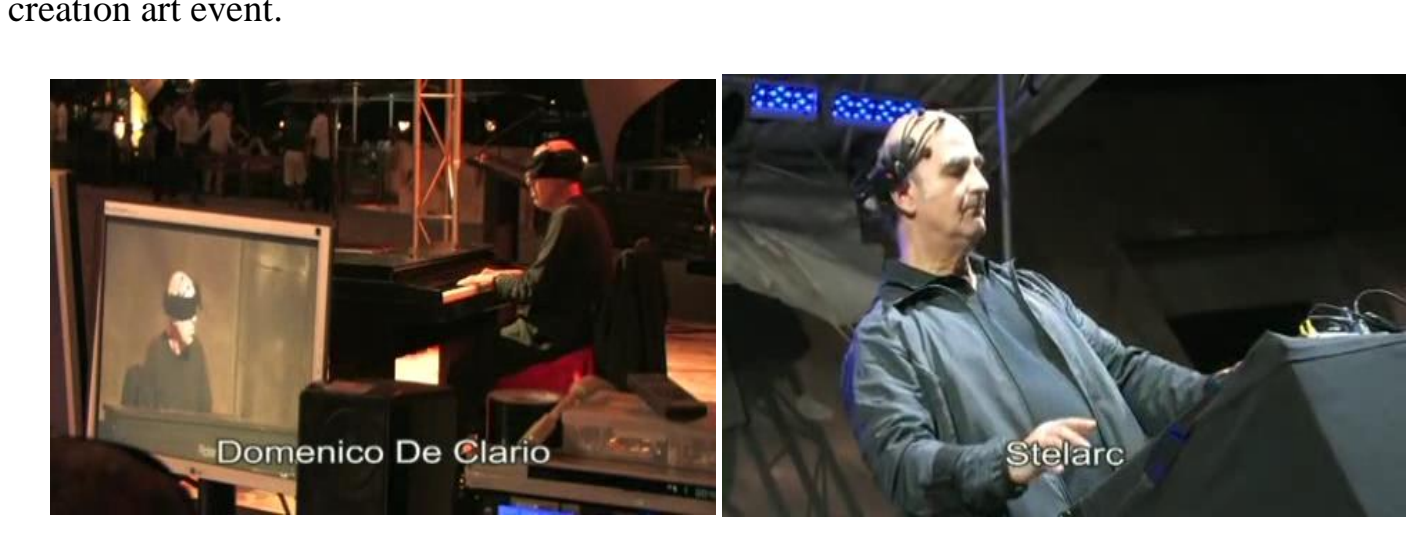

Figure 7. Global Mind Project, 2010

The next case work calls 'The subConch' and it is a mind control musical instrument project. The subConch is a completely new musical instrument that can be played by using the force of your mind alone. The instrument, a conch shaped metallic sculpture, is hung from the ceiling in three steel wires. Along with the conch comes a headset that you, the performer, must wear. The headset reads the players mind using EEG technology allowing control over 
pitch and other audio characteristics. To gain this control the user must sit down and follow a three minute training program. When finished he or she will have the ability of complete cognitive control.

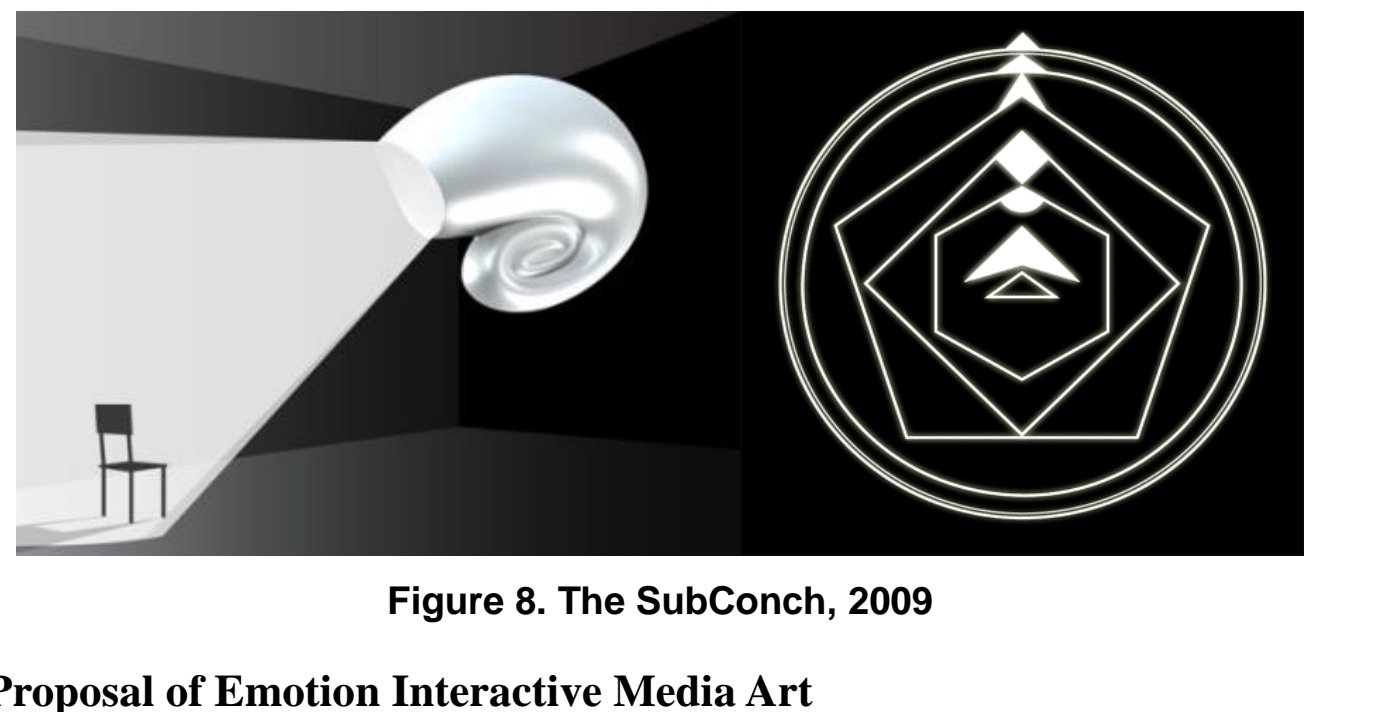

\section{Proposal of Emotion Interactive Media Art}

This chapter is about the Media Art that uses Facial Expression recognition system.

4.1 is about the concept of Emotional Interactive Media Art and we named it "The Universe; We all have been".

\subsection{Emotion Interactive Media Art Concept (The Universe)}

The Emotional Interactive Medta Art calls 'The Universe' use a facial expression which represent the audience emotion recognition as an interactive art works method. Universe, the space of Universe is expressed relation with mother's womb. The subtitle 'We all have been....' is to explain the mean that we all passed the space literally. This art work was designed for experience the mystique of the space that we cannot remember. This art work will be complete through the audience face expression.

\subsection{Narrative (User Scenario)}

The art works 'The Universe' will be creating with the key element of Media Art that we analyzed in Chaper 2 and also will apply the Facial Express Recognition system. When audience stands in the installation, they can see some positive and negative image of fetus, children and mother. The facial expression recognition system will analyze the audience's emotion through face expression. After check the emotion the installation environment color will changes according to the Wheel of Emotion chart. 


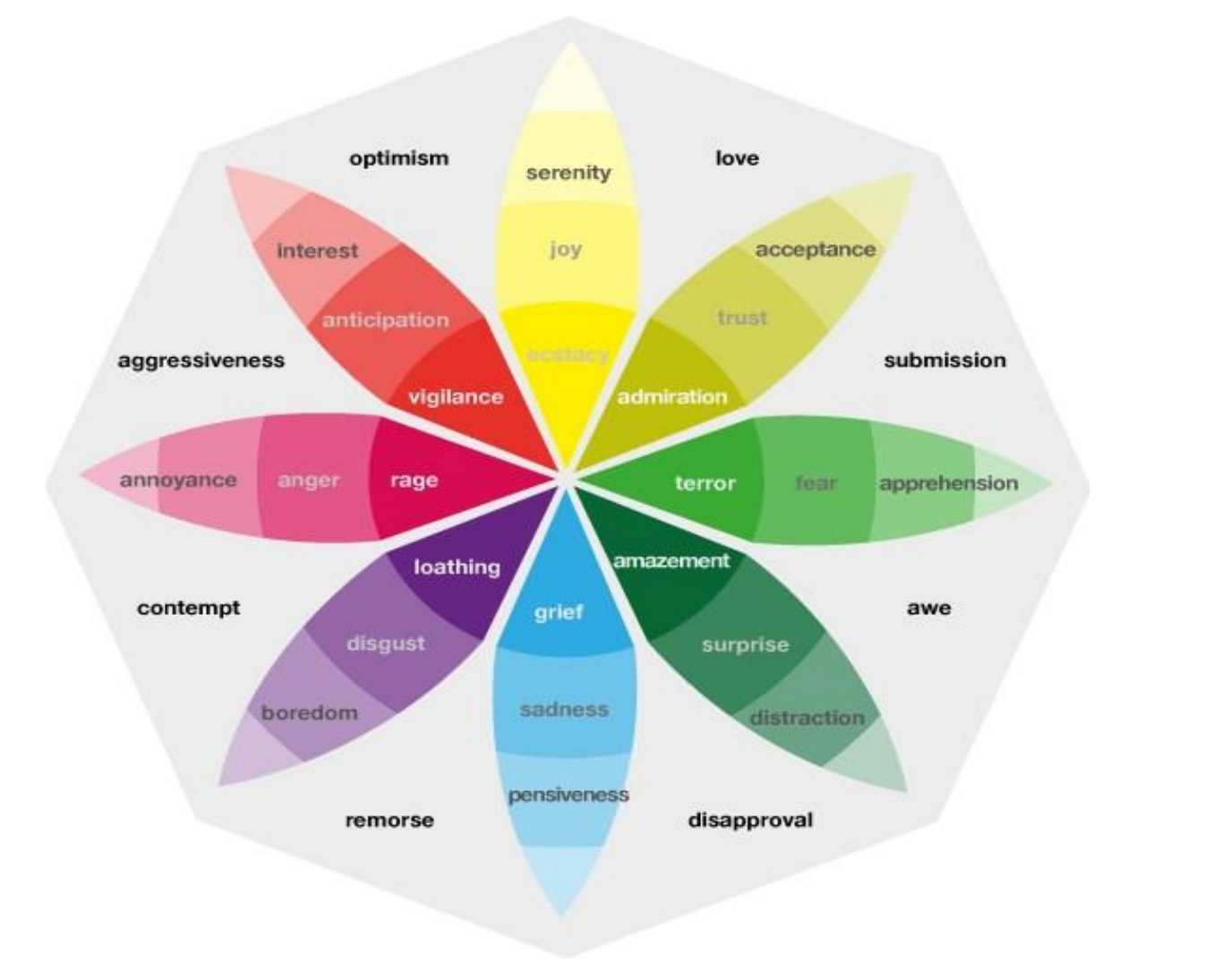

Figure 9. Emotion Model chart of Robert Plutchik (Wheel of Emotions)

The audience will use the Emotion Interaetive Media Art with below method. We described the Media Art implementat on purpose and contents about accessibility, immerses, Interaction and the result in Table 1 .

\section{Table 1. Media Art Implementation Purpose}

\begin{tabular}{c|c}
\hline & \multicolumn{1}{c}{ Contents } \\
\hline Easy accessibility to the Media Art works & Galaxy images to represent 'The Universe' \\
\hline Immersion & Immersion using Virtual Reality \\
\hline Interaction & $\begin{array}{c}\text { Audience face expression interact with images and } \\
\text { sounds }\end{array}$ \\
\hline Result & $\begin{array}{c}\text { According to the audience's emotion the virtual } \\
\text { environment color and sound changes. }\end{array}$ \\
\hline
\end{tabular}

And we described hardware spec and software spec about Emotion Interactive Media Art implementation in Table 2 and Table 3.

Table 2. Hardware Spec

\begin{tabular}{c|c}
\hline Category & H/W Spec \\
\hline CPU & Intel ${ }^{\circledR}$ Core ${ }^{\mathrm{TM}} 2$ Quad CPU $2.40 \mathrm{GHz}$ \\
\hline RAM & $4 \mathrm{~GB}$ \\
\hline
\end{tabular}




\begin{tabular}{c|c}
\hline VGA & Nvidia GeForce GTS 250 \\
\hline Bluetooth Sensor & Bluetooth 4.0 \\
\hline Kinect & Kinect \\
\hline Beam Projector & BENQ Beam Projector \\
\hline
\end{tabular}

Table 3. Software Spec

\begin{tabular}{c|c}
\hline Category & S/W Spec \\
\hline OS & Windows 7 \\
\hline Programming Tool & Open NI \\
\hline Graphic Tool & Adobe Photoshop CS 5 \\
\hline
\end{tabular}

For the future work, we are going to use web camera to recognize the user's facial expression and shows images and sound changes to them. Moreover, for the installation below related image will help to create the installation and the interface.

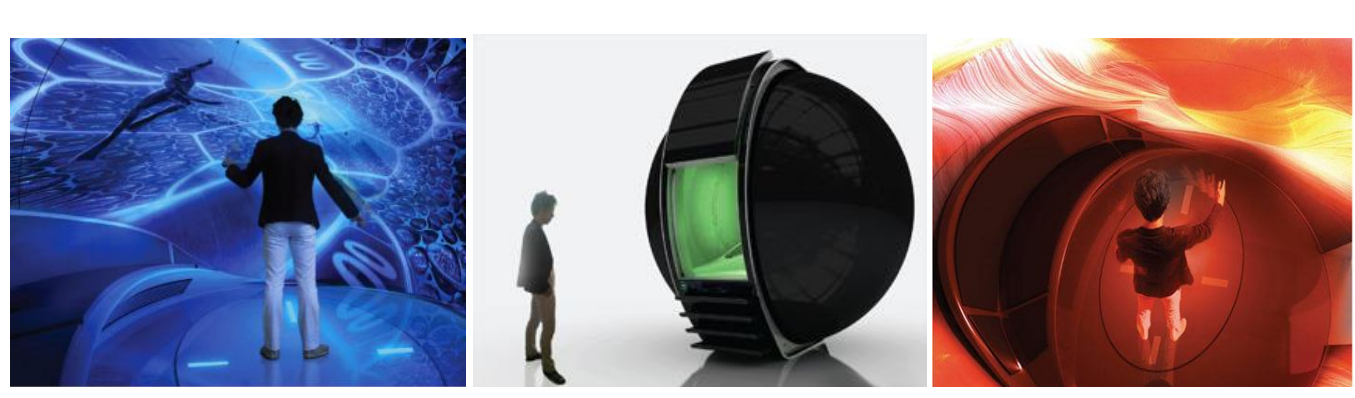

Figure 10. Immersive Virtual-reality 'Cocoon'

\section{Conclusion}

People whowatch, use and participate with art works, they feel something from it. Therefore, we researched for 'The Universe' apply Emotion Recognition system to Interactive Media Art for creating and developing a new art works that response in a real-time according to the audience's emetion.

\section{References}

[1] F. Popper, Art of the electric age", Thames Hudson, London, pp. 8, (1993).

[2] A. Darley, "Visual digital culture: Surface play and spectacle in new media genres", London: Routledge, (2000).

[3] R. Greene, "Internet art", London, Thames \& Hudson, (2004).

[4] J.-B. Jung, "A definition and Applications of Emotion in computer game and human sensibility engineering", The Korean Society for Computer Game, pp. 34, (2005).

[5] http://thedigitalage.pbworks.com/w/page/22039083/Myron\%20Krueger.

[6] H. Y. Lee, "Interactive Digital Art based on user's Physical Effort with Sensor Technology", IJSEIA vol. 8, no. 3, (2014).

[7] H. Y. Lee, "Digital Game Art based on Sensor Technology", Jeju Island, Korea, Workshop, (2013).

[8] K. J. Won, "Interaction Relation and Extended Expression of New Media Art in Plastic Art", Kim Jae Won, pp. 102, (2012). 
[9] M. Tribe and R. Jana, "New Media Art", Taschen: KoIn, (2008).

[10] http://www.oxforddictionaries.com/us/definition/american_english/cyberspace.

[11] ]기술과 예술-미디어 아트의 확산 현상을 중심으로 p.63 64 고려대학교 대학원 석사학위 논문, 임종인, (2010).

[12] W. K. Yi, "Digital image and virtual space", Yonsei University Press, (2004).

[13] "Theories of Emotion", Psychology.about.com, (2003).

[14] "Telecommunications Review and Perspectives on Emotion Recognition Technology, vol. 19, no. 5, (2009), pp. 774-775.

[15] http://we-make-money-not-art.com/archives/2006/02/shu-min-lins-wo.php.

[16] http://www.telepresenceoptions.com/2008/09/designers_developing_virtualre/.

\section{Authors}

Hae-Young Lee, was born in Seoul, Republic of Korea. She received Master of Design Science (Digital Media) in the University of Sydney in 2008. She is a candidate of Art and Technology Ph.D. at Chuang-Ang University. Her current research interests are Media Art, Digital Art Game and Emotion Engineering.

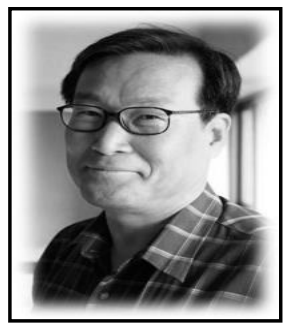

Won-Hyung Lee, he received M.S. degree from the Kookmin University in 1988 and Ph.D. degree at University of N.S.W. in 1998. From 2002, he is a presiden of Korean Society for Computer Game and he is currently a professor with the Graduate School of Advanced Imaging Science, Multimedia, and Film, Chung-Ang University, Seoul, Korea where he leads the Culture technology/Game Lab. His research interest include computer game technology, information protection and game AI, game rendering.

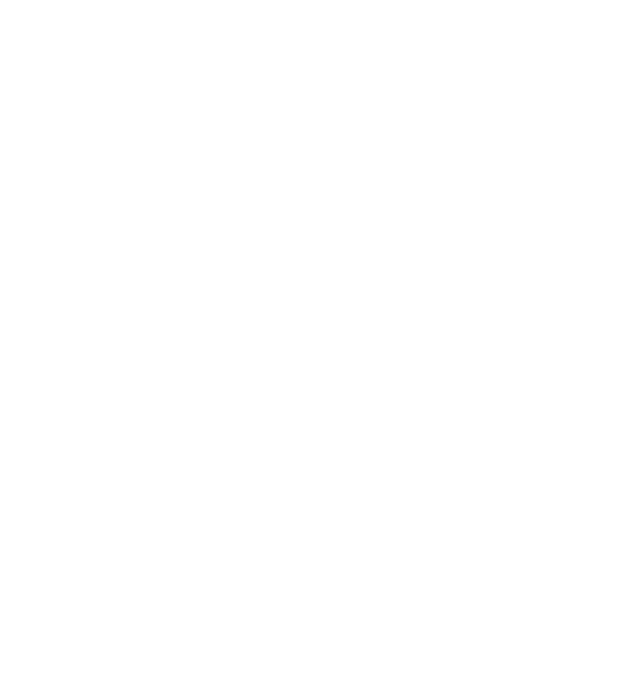

